\title{
4
}

\section{An action research role for teachers}

\author{
Frank (Nick) Nicassio
}

Information Resource Center

Umatilla-Morrow ESD, Oregon, USA

\section{ABSTRACT}

Observations made in four schools during the course of a videodisc instruction project and selected results drawn from a recently conducted survey are used to discuss teachers' roles, responsibilities, and concerns with respect to the integration of information technologies into instruction. These observations and results provide the basis for a proposal to enlarge on teachers' responsibilities to include action research, a role which holds promise for simultaneously promoting effective instruction, improved student learning, and the creation and maintenance of an environment receptive to the constructive introduction of helpful technological innovations.

Keywords: attitudes, collaborative learning, information technology, integration, research

\section{INTRODUCTION}

For several years now, the Information Resource Center (IRC) has been integrating information technologies (IT) into various educational activities. The invitation to write this paper has provided an opportunity to reflect on our work, and what we have learned about teacher roles and concerns and their relationship to the delivery of high quality instruction.

Following brief background comments about the context of the IRC's work, I will discuss teachers' roles as observed during an IRC led project 
to integrate videodisc instruction into four demonstration classrooms. Selected results from a recently conducted survey of our educational service area will be cited to enlarge on the observations. These results and observations motivate a proposal to extend teachers' responsibilities to include action research, a role which holds promise for simultaneously promoting effective instruction, improved student learning, and IT integration.

\section{THE CONTEXT OF OUR WORK}

The IRC is a program of the Umatilla-Morrow ESD (UMESD) Student Services Department. UMESD is a regional education centre providing instructional and indirect services to nearly 13,000 students enrolled in 13 school districts in rural northeast Oregon. The UMESD's service area of 66,800 residents consists mainly of small farming and logging communities scattered across 13,500 square kilometres of river valleys, high plateau, and mountains. Our largest school district, located in the Columbia River Basin, enrolls more than 3,500 students in kindergarten through grade 12; our smallest, located in the Blue Mountains, enrolls 50.

Though students are few in number, their needs are as diverse as those of students in many urban areas. During the 1992-1993 school year, for instance, UMESD's Student Services Department instructed over 2,400 Hispanic, Native American, migrant, and at-risk students attending classes in 35 separate buildings. In addition, instruction, therapy, and consultation were provided in the classrooms and homes of nearly 2,500 disabled pre-school and school-aged students.

The organizational and educational challenges presented by geographic remoteness and student diversity have drawn us increasingly to the use of IT to improve student and staff performance. The IRC collaborates with UMESD and local school personnel to integrate IT into selected activities intended to promote student learning and teacher effectiveness. For example, IRC staff have developed computer-based data systems to enhance decision making by multidisciplinary educational teams [1], and to improve multi-agency services for at-risk infants and school children [2]; created a computer-based procedure to improve the quality of psycho-educational reports [3, 4]; established videodisc instruction in middle school classrooms [5]; and have recently begun planning the use of videodisc, $\mathrm{CD}-\mathrm{ROM}$, data scanning, and telecommunication technologies to improve the instructional effectiveness of teacher and para-educator 
teams. Each of these innovations remains operational, the oldest being active for the past ten years.

\section{THE ROLE OF TEACHERS}

\section{Teachers introducing a technological innovation}

The IRC's most recent operational endeavour in IT integration began in 1990 when UMESD funded videodisc demonstration sites within four of our 13 school districts with the goal of helping teachers provide high quality mathematics and science instruction to mildly handicapped, non-handicapped, and talented and gifted students, who are educated in the heterogeneously grouped classrooms characteristic of our rural area. Videodisc (laserdisc) technology promised to be one means by which teachers within established classrooms could adapt existing curriculum and their own instructional methods to meet a more diverse array of learning needs for students of 11 to 15 years of age.

Our initial choice of instructional laserdiscs was the "direct instruction" oriented Core Concepts in Mathematics and Science series which was validated for the National Diffusion Network by its principal developer, Utah State University. We subsequently added The Adventures of Jasper Woodbury, an "anchored instruction" oriented series which was, at the time, under development by the Learning Development Center at Vanderbilt University. Teachers have since integrated both programs into classrooms where they now serve approximately 705 students annually with generally favourable learning outcomes [5].

I believe that the high quality of laserdisc instruction contributed in large measure to our success. I also attribute success to the roles teachers assumed as they wrestled with the complexities associated with introducing a technological innovation into established classroom routine. We had approached the integration of instructional videodisc in a planned and systematic manner hoping to deepen its penetration into daily classroom practices, amplify its impact on teacher enthusiasm, and increase its effect on student performance. But, our efforts were also motivated by a desire to have teachers' roles emphasize collaborative inquiry and action. Why? Because it is these qualities, I believe, that aid in creating and maintaining an educational environment receptive to the constructive introduction of significant changes, including instructionally effective technological innovations. Let us review the process by which we attempted to foster these qualities. 


\section{A process to foster collaborative inquiry and action}

We established the four demonstration sites on the recommendation of a two-county co-ordinating council. Following approval by local district superintendents, we solicited potential sites with a "request for proposals" distributed to each school in our service area. District co-ordinating council representatives responded to initial queries from schools. Four sites submitted proposals to the IRC which subsequently made visits to show a videotape featuring laserdisc instruction, to answer questions and clarify goals, and to emphasize that criteria for selection required a school to establish a team responsible for both videodisc instruction and evaluation.

The IRC then asked each of the four school sites to decide on team membership and to discuss team options for effectively integrating videodisc technology into instructional programs, a step which took two months to accomplish. The four resulting teams varied in size and role composition, but consisted of at least two regular classroom teachers, one special education teacher, and the building principal. Other personnel that were also involved included: a special education director, a speech and language therapist, a student services coordinator, a parent, a curriculum consultant, and two media specialists.

Our initial assumptions about the importance of establishing "teams" was confirmed in June 1993 by an IRC survey of educators (teachers, principals, para-educators) who have been actively engaged in IT integration efforts throughout our service area. In that survey, every respondent $(\mathrm{N}=21)$ acknowledged that, in addition to teachers, other personnel were crucial to the integration and effective utilization of information technologies. The survey emphasized the importance of a wide range of personnel, including media specialists, resource specialists, classroom assistants, technicians, technology specialists, principals, assistant superintendents, secretaries, school boards, universities, researchers, parents, students, teacher teams, and school-governance councils. These persons were judged important because they provided access to resources, enhanced the integration process, applied technology directly to student learning, and added a new air of collaboration to the educational process.

Although teachers have special instructional responsibilities obliging them to focus IT efforts on teaching and associated activities, our survey data suggest that they are functionally dependent upon support personnel to realize their objectives. Consequently, it becomes imperative for teachers and related education personnel to collaborate in their efforts to organize IT in valuable and productive ways. 
Following the preliminary discussions cited above, each school team prepared a draft of a First Year Implementation Plan which was submitted to the IRC for review. The IRC then provided hardware, software, training, and a two-day field trip to a neighbouring state so that teams could directly observe laserdisc instruction in classrooms.

Upon return, teams wrote their final First Year Implementation Plan which, among other things, specified: the names of the school's team leader, each team member, and a research journal keeper; videodiscs, adopted texts, and enrichment materials to be used for instruction; and the standardized and informal assessments to be used for evaluating laserdisc effects. They also included how the team would structure staff responsibilities, class assignments, and instructional time to insure active student participation; a description of three adaptive curriculum strategies to be used in conjunction with videodiscs for the benefit of disabled students; and supportive assistance the team would require from the IRC.

Formulation of the Implementation Plan not only committed each team to a collaborative and systematic trial using laserdisc instruction, but also to a collaborative and systematic evaluation of the effects of that instruction on teacher perceptions and student learning. Under the plan, each site would submit its findings to the IRC in the form of follow-up questionnaires, formal and informal student performance measures, a research journal, a written narrative summarizing all data and anecdotal observations, and a modified Implementation Plan for the subsequent year.

Over the four years of the project, the IRC has invited sites to an annual, day long, working meeting held at the beginning of the new school year. These meetings have provided the means for teams to share their findings, discuss their experiences and insights, suggest modifications for successive instructional trials, and recommend additional training. Results have also been shared at local, regional, and international meetings. Team recommendations for additional software and training have led to the acquisition of other videodisc programs, the offering of college credit for practicum experiences, and a workshop on multimedia technology.

The above portrayal should not be interpreted as a smooth and flawless integration, however. It was not. Teachers always operate in a complex environment of interdependence between instruction, technology, and human relations. Our implementation was no exception. As a consequence, we experienced periods of higher and lower motivation, diminished commitment, discontinuities resulting from staff turnover, technical problems, and difficulties in correlating instructional objectives presented on videodisc with objectives presented in textbooks and in state 
curriculum guidelines. Also, extending the program beyond model sites has progressed more gradually than anticipated.

What we created, however, was a socio-technical environment in which teacher roles and responsibilities for instruction were sustained by a larger constellation of administrative support, technical assistance, in-service, cooperation within and among teams, and IT utilization. I believe it is exactly this kind of collaborative environment that can assist teachers as they labour over the many complex problems they confront daily. Our June 1993 survey revealed, for instance, that teachers' IT integration concerns clustered around three themes:

- barriers to full access and full utilization of existing technologies;

- lack of personal preparedness;

- technology's potential for unanticipated negative consequences.

Each of these areas of concern could be constructively addressed in an environment that provides administrative support, technical assistance, in-service, and active cooperation.

In addition, we also established an action research context in which teams defined input (independent) and output (dependent) variables, specified outcome measures, modified successive trials based on empirical evidence, and shared their findings with other professionals. Callister and Dunne have noted that technology dazzle can induce teachers into accepting instructionally ineffective software packages" ... even if it means denying the evidence of personal experience" p. 325 [6]. To overcome this tendency, educational practices must encourage teachers to make data-based decisions and mid-course corrections in order to modify potentially effective technologies for the benefit of effective student learning. I believe the adoption of action research represents an important step toward fostering to a greater degree than currently practised, these conditions of collaborative inquiry and action.

\section{A PROPOSAL TO EXTEND TEACHER ROLES TO INCLUDE ACTION RESEARCH}

Kemmis and McTaggart [7] describe action research as a process by which members of a school community (teachers, administrators, students, parents, school boards, support personnel) can work collaboratively toward improvement and change in their schools. There are variations on the action research theme, of course [7 - 13], but most provide for thinking systematically about what happens in schools, implementing critically 
informed actions, and monitoring and evaluating the effects of the action with a view towards continuous improvement and ongoing collaboration with others who share a common concern [7]. Action research may, thus, be described as a process of collaborative thinking, action, and adaptation for the purpose of improving teaching and learning. It may also be thought of as a process by which schools can collaboratively adapt information technologies to attain their important educational goals and instructional objectives.

The American passion over the last decade for educational reform and restructuring [14] has, coincidentally, set the stage for teachers and related personnel to assume the collaborative action research role proposed by this paper. Federal legislation such as the Technology for Education Act of 1993 [15] with an interest in technology diffusion in schools, and state legislation such as Oregon's Educational Act for the 21st Century [16] with its mandate for decentralized school-based decision-making, should make it increasingly possible for a growing number of teachers, administrators, and para-educators like those we surveyed to assume an active role in determining effective uses of information technologies in the instructional, administrative, and organizational activities of their schools.

How might educators join technology and education together in a productive discussion? By adapting Sirotnik's dialectical inquiry-action cycle [13], school-based action research teams could ask the following questions and take the following actions.

- What are our current beliefs and practices with respect to student learning experiences (or professional technical training, or instruction in literature, or governance of the school site, or gender equity in mathematics and science instruction, or full inclusion of disabled students in mainstream classrooms ...)?

- How did we come to hold these beliefs and employ these practices?

- Whose interests are, and are not, being served by these beliefs and practices and in what ways?

- What information and knowledge do we have or need to get hold of that may illuminate this discussion about beliefs and practices?

- Is the current state of affairs the way we want it to be?

- What are we going to do about it?

- Can information technologies extend our capacities to achieve our proposed actions? If so, how can we incorporate their use into our plan?

- Take actions relevant to our plan, monitor these actions, and then repeat this inquiry-action cycle. 
Participants are encouraged to invite a small group of colleagues to select a technology issue of interest and ask the questions contained in this inquiry-action cycle in order to better grasp the complex interdependencies between instruction, technology, and human relations confronting teachers on a daily basis. This little experiment may help a consideration of how teachers and related support personnel might clarify the circumstances under which they must work and learn together in order to create and maintain an environment receptive to the constructive introduction of helpful technological innovations. It may also suggest the salutary effect that collaborative inquiry can have on the successive trials of an implementation.

Technologists may complain that collaborative inquiry and action are irrelevant to the integration and effective use of information technologies. I would contend, however, that ignoring the sort of dialogue stimulated by Sirotnik's inquiry-action cycle is precisely the reason that, "... over the past dozen years ... technology has not revolutionized learning in the classroom, nor led to higher productivity in schools" [14], p.188. By not subordinating our interests in technology to a larger discussion about the socially legitimate work of education, and how that work is to be sustained in the classroom on a daily basis, we have diminished IT's potentially beneficial impact on schooling. Rhodes of the American Association of School Administrators has noted, "Sadly because of these flaws in our perception of schools, the 'work' they do and how they do it, we have today numerous examples of technology's effectiveness with real children, in real classrooms. But without a context within which to make sense of them, they appear as isolated demonstrations of technology" [17], p.3. Action research can provide teachers "a context within which to make sense"; a context of joint inquiry, mutual consensus building, collective planning, concerted action, and the generation of empirical feedback against which to evaluate current efforts.

Enthusiastic collaboration among all participants (teachers, principals, para-educators, school boards, parents, students) in the educational process is the key to defining and solving problems about daily educational practices. Only in this constructive atmosphere can specific technologies be modified, over successive trials, to address desirable goals. Adoption of collaborative problem framing and collaborative action taking, of the type defined by Sirotnik's inquiry-action cycle, would mark a new and emerging role for teachers, and would clear the way for the genuine integration of information technologies into daily educational practices. It would also alleviate many of the teacher concerns identified by our survey. 
In conclusion, we must acknowledge that some people will take the position that technology is an essential yet only small part of the education equation [18], while others will take the more radical stance that economic progress is dependent on the rapid and total replacement of conventional schooling by a new commercial industry based on technology [19]. Whatever stance political pressures push education in the direction of, an action research role has potential for enabling teachers and the related personnel upon whom they depend to simultaneously promote effective instruction, improve student learning, and integrate information technologies into daily educational practice.

\section{Acknowledgments}

I would like to thank Dr. Robert Earl, Dr. Dean Thompson, William Miller, Suann Ritchie, and William Taylor for their critical comments of an earlier draft of this paper. Thanks also to Karen Overstreet, Tricia Towne, and Karen Hoeft, the staff of the Information Resource Center who make its work possible.

\section{REFERENCES}

1. Nicassio, F.J., \& Overstreet, K.K. (1993) A total picture of the child. Educational Information Resource Management Quarterly, 2 (3), 18-22.

2. French, R.B., Overstreet, K.K., \& Nicassio, F.J. (1991) Community networking, early identification, and electronic information systems. In, The Oregon Conference Monograph, 159-165. Eugene, OR: University of Oregon.

3. Nicassio, F.J., \& The Staff of The Child Development Program. (1986, Spring) Allegro: A system for creating psychoeducational reports using a word processor knowledge base. Computers in Psychiatry/ Psychology, 8 (1), 5-11.

4. Nicassio, F.J., Moore, K.J., \& The Staff of The Child Development Program (1986, July) Computer support in a rural setting: A comparison of computer-assisted and handwritten evaluation reports. Psychology in the Schools, 23, 303-307.

5. Nicassio, F.J., Thompson, D., Burk, J., Wright, K., Palmer, N., McBride, M., \& Shubert E. (1993) Laserdisc Technology in the Rural 
Classroom: A Case Study of Anchored Instruction in Mathematics and Science. A. Knierzinger, \& M. Moser (Ed.), Informatics and Changes in Learning: Proceedings of the IFIP Open Conference. Gmunden, Austria. International Federation for Information Processing, XVIII:1-4.

6. Callister, T.A., \& Dunne, F. (1992) The computer as doorstop: Technology as disempowerment. Phi Delta Kappan, 324-326.

7. Kemmis, S., \& McTaggart, R. (1988) The action research planner. Geelong, Victoria: Deakin University Press.

8. Goswami, D., \& Stillman, P. (1987) Reclaiming the classroom: Teacher research as an agency for change. Upper Montclair, NJ: Boynton/Cook Publishers, Inc.

9. Joyce, B., Wolf, J., \& Calhoun, E. (1993) The self-renewing school. Arlington, VA: Association for Supervision and Curriculum Development.

10. Mohr, M.M., \& Maclean, M.S. (1987) Working together: A guide for teacher-researchers. Urbana, IL: National Council of Teachers of English.

11. Nicassio, F.J. (1992, January/February) SwampLog: A reflection in action journal process. The Writing Notebook, 9 (3), 13-18.

12. Reason, P. (Ed.). (1988) Human inquiry in action: Developments in new paradigm research. Newbury Park, CA: Sage Publications.

13. Sirotnik, K.A. (1987) Evaluation in the ecology of schooling: The process of school renewal. In J. Goodlad (Ed.), The ecology of school renewal. Eighty-sixth Yearbook of the National Society for the Study of Education: Part 1. Chicago, IL: University of Chicago Press, 41-62.

14. Conley, D.T. (1993) Roadmap to restructuring: Policies, practices and emerging visions of schooling. Eugene, OR: ERIC Clearinghouse of Educational Management, University of Oregon.

15. SB1040 (1993) Technology for Education Act of 1993: United States Senate Bill 1040: Executive Summary. Educational Information Resource Management Quarterly, 2 (4), 30-34.

16. HB3565 (1991) Oregon Educational Act for the 21st Century: House Bill 3565. The 66th Oregon Legislative Assembly, Regular Session.

17. Rhodes, L. (1993) What to do until technology legislation arrives. Arlington, VA: American Association of School Administrators. 
18. (1992) School reform: Why we need technology to get there. Electronic Learning, 22-28.

19. Perelman, L.J. (1992) Hyperlearning: Clinton's greatest opportunity for change. Discovery Institute Inquiry. Seattle, WA: Discovery Institute.

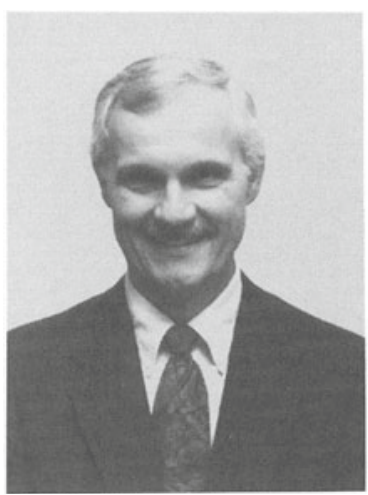

Nick Nicassio is a resource specialist for the Umatilla-Morrow Education Service District where he coordinates the Information Resource Center. Nick received his $\mathrm{PhD}$ in Educational Psychology from the University of California, Santa Barbara, and serves as adjunct faculty member for Oregon State University Division of Continuing Higher Education. $\mathrm{He}$ is a member of the American Educational Research Association, the American Psychological Association, the American Psychological Society, the Association for Humanistic Psychology, the National Society for the Study of Education, the International Society for Technology in Education, the Association for Supervision and Curriculum Development, and Phi Delta Kappa - Eastern Oregon Chapter. 